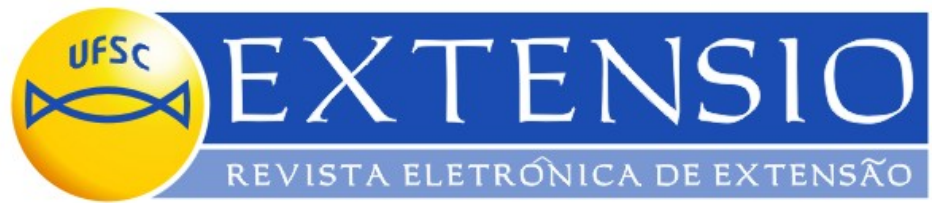

\title{
A CRIANÇA PROTAGONISTA NA CONSTRUÇÃO DE BRINQUEDOS COM SUCATA E MATERIAL RECICLÁVEL NO ESPAÇO DO LABRINCA
}

\author{
Fernanda Pimentel Pacheco \\ Acadêmica do Curso de Psicologia da UFSC \\ Ma. Leila Lira Peters \\ Doutoranda em Psicologia pela UFSC \\ Dra. Denise Cord \\ Doutora em Engenharia de Produção pela UFSC \\ Paulo Roberto Brzezinski \\ Professor do Colégio de Aplicação da UFSC (Coordenador do LABRINCA) \\ paulorb@ca.ufsc.br
}

\section{Resumo}

A observação e estudo das interações das crianças entre si, com os professores e com os objetos, no caso, brinquedos, foi o objetivo do trabalho realizado. Baseando-se na teoria históricocultural, as análises apontam para a possibilidade de se organizarem estratégias didáticopedagógicas abertas à criatividade e ao protagonismo infantil, potencializando a utilização de materiais recicláveis.

Palavras-chave: Brinquedo. Sucata. Criatividade.

\section{THE CHILD PROTAGONIST IN THE CONSTRUCTION OF TOYS WITH SCRAP AND RECYCLABLE MATERIALS ON SPACE OF LABRINCA}

\begin{abstract}
The observation and study of interactions children's between themselves, with teachers and objects, in this case, toys, was the objective of the performed work. Based on the historicalcultural theory, the analysis points to the possibility of organizing didactic-pedagogical strategies open to creativity and the infantile protagonist, increasing the use of recyclable materials.
\end{abstract}

Keywords: Toy. Scrap. Creativity. 


\section{Introdução}

O LABRINCA (Laboratório de Brinquedos do Colégio de Aplicação) constitui-se em um projeto interdisciplinar, envolvendo professores e alunos dos cursos de Pedagogia, Educação Física, Biblioteconomia, Psicologia e Arquitetura que se reuniram para desenvolver um projeto que articulasse pesquisa, ensino e extensão. O Colégio de Aplicação (CA) é caracterizado como uma instituição que tem por objetivo experimentar novas formas de relação ensinoaprendizagem. Por ser o sorteio, a forma de ingresso dos alunos no CA, o colégio é frequentado por crianças moradoras de diferentes locais da Região da Grande Florianópolis, de diferentes segmentos sócio-econômicos e de diferentes registros culturais.

O funcionamento do LABRINCA iniciou no ano letivo de 2003, inserido no contexto escolar em período regular de aula. $\mathrm{O}$ atendimento é realizado pelos bolsistas - atualmente alunos de Psicologia e de Educação Física - que realizam diversas atividades para o funcionamento do espaço, recebendo, para isso, bolsa remunerada de estágio não obrigatório. Cada turma é dividida em dois grupos, os quais são levados pela professora até o LABRINCA, em horário estabelecido, permanecendo no espaço durante $45 \mathrm{~min}$. (tempo referente a uma aula), e, enquanto metade da turma permanece na brinquedoteca, a outra metade participa de atividades desenvolvidas na biblioteca.

A ideia de montar um laboratório de produção de conhecimento sobre o tema infância/ludicidade surgiu de dois fatores: da necessidade de criar um espaço dedicado para arquivar as descrições de brincadeiras e de jogos tradicionais pesquisados por alunos de Educação Física do Colégio de Aplicação da Universidade Federal de Santa Catarina e, ao mesmo tempo, possibilitar o acesso à experimentação de uma variedade de jogos e brinquedos que não eram disponibilizados aos alunos do Colégio de Aplicação.

É importante destacar que, no ambiente escolar, o jogo, o brinquedo e a brincadeira, que dão suporte para as atividades lúdicas, são compreendidos como educativos na medida em que as situações lúdicas são intencionalmente criadas pelo adulto para trazer ao processo de ensinoaprendizagem condições para maximizar a construção do conhecimento. Neste sentido, para Kishimoto (1999), o brinquedo educativo possui a função lúdica (por propiciar diversão, prazer e até desprazer, quando escolhido voluntariamente pela criança) e educativa (ensina qualquer coisa que complete o indivíduo em seu saber, seus conhecimentos e apreensão do mundo). 
A atenção crescente aos direitos da criança fez surgir, conforme Pinto e Sarmento (1997), uma novidade na atual preocupação com o mundo infantil: a importância da participação efetiva dessa população na sociedade, assegurando-lhe a autonomia e o estatuto de atores sociais como direito. É exatamente nesse sentido que se estrutura a proposta do brincar com sucata em espaço ${ }^{1}$ privilegiado, com o intuito de trazer a criança para perto da transformação e da criação, proporlhe a participação ativa, o fazer e a vontade de lidar com materiais aos quais ela própria dará a forma, inserindo-a na produtividade de cultura e afirmando ainda mais seu direito de brincar, livre e com espontaneidade. O brinquedo-sucata permite, a quem brinca, desvendá-lo, (re)significá-lo, pois é um objeto que possui inúmeros sentidos que não são óbvios e nem estão evidentes.

A sucata e a brincadeira com ela podem ser fonte de transformação e tomada de consciência acerca da realidade, pois, como mostra Machado (1995, p.27)

[...] enquanto usa, manipula, pesquisa e descobre um objeto, a criança chega às próprias conclusões sobre o mundo em que vive. Quando puxa, empilha, amassa, desamassa e dá nova forma, a criança transforma, brincando e criando ao mesmo tempo. Poder transformar, dar novas formas a materiais como quiser, propicia à criança instrumentos para o crescimento saudável, que a estimulam a explorar o mundo de dentro e o mundo de fora, dando a eles nova forma, no presente e no futuro, a partir de sua experiência [..]

Nessa atividade lúdica construtiva, também entram limites e regras, que são ponte entre subjetividades e objetividades, são introduções ao princípio da realidade na medida em que as crianças são desafiadas a concretizarem seus projetos. "A concepção de um brinquedo implica reflexão, percepção e observação do objeto com o qual seja possível brincar ou jogar” (SOLÉ, 1992. p. 37). Na execução desse projeto criativo, a criança também trabalha sua autoimagem e sua autoestima, reconhece-se e reconhece o outro.

No que concerne a extensão, tarefa primordial dos centros de produção de conhecimento como a UFSC, o LABRINCA se apresenta como um laboratório de observação e experimentação que tem despertado o interesse dos educadores tanto no aprofundamento dos estudos dos processos de ensino-aprendizagem, como nas questões organizacionais. Tem-se em vista que as instituições de sistemas de ensino voltam-se para o período integral de aula e também como a atual obrigatoriedade da entrada de crianças com 5 anos de idade nas séries iniciais.

\footnotetext{
${ }^{1}$ A Brinquedoteca LABRINCA (Laboratório de Brinquedos do Colégio de Aplicação) consolida-se como um espaço de brincar, inserido no universo escolar, que tem como objetivo geral propiciar o acesso a uma variedade de jogos, brinquedos e fantasias aos alunos do ensino fundamental, por meio da expressão e da experimentação da cultura lúdica infantil. (PETERS, 2004).
} 
Compreender o processo criativo nesse contexto permite (re)significar as relações da criança e do adulto dentro da escola, possibilitando novos olhares acerca dos processos de escolarização e de constituição de identidades, visando à abertura de novas perspectivas de mediação do profissional da escola no que diz respeito aos processos de ensino e de aprendizagem.

\section{Material e Métodos}

Entre os objetivos do LABRINCA, destacam-se como parâmetros para pesquisa aqui relatada:

1) constituir-se como um espaço privilegiado para a observação e pesquisa sobre a interação de crianças em jogos de faz-de-conta e de regras, bem como em processos de aprendizagem propiciados pelos jogos, brinquedos e brincadeiras;

2) desenvolver protótipos de brinquedos e jogos com materiais variados, inclusive de sucata e materiais recicláveis, com especial atenção para o desenvolvimento de recursos para crianças com necessidades especiais;

3) constituir-se em campo de estágio e pesquisa aos alunos e professores de diferentes cursos de graduação e pós-graduação da UFSC.

Diante destes objetivos, e considerando a criança protagonista na construção de brinquedos com sucata e material reciclável no espaço do LABRINCA, o adulto mediador, ciente de que o processo criativo está unido ao princípio de realidade, apresenta e organiza a atividade, dando liberdade à criança de executá-la da maneira como preferir, prevalecendo a espontaneidade. Quando é permitido que a criança reinvente, a partir da reciclagem, está sendo viabilizado seu desenvolvimento não só pela descoberta de algo novo, mas também pela apresentação de alternativas para a formação de sua escala de valores.

O incentivo ao processo criativo, como uma proposta de protagonismo infantil no contexto escolar, pôde ser exemplificado pelo incentivo à elaboração de brinquedos com sucata e material reciclável por um grupo de 23 crianças de $1^{\text {a }}$ série do Ensino Fundamental do Colégio de Aplicação da Universidade Federal de Santa Catarina.

Nesse processo, analisado à luz da perspectiva histórico-cultural, foram evidenciados, nas relações dialógicas entre criança-criança, criança-brinquedo e criança-adulto, indícios que 
pudessem explicitar o processo criador, bem como características dessa atividade e seus possíveis resultados ao desenvolvimento de identidades.

A coleta de dados ocorreu por meio de filmagem em VHS para captar nuances nas relações entre seus agentes e suas ações (MEIRA, 1994). Foram registrados quatro encontros, cada qual com aproximadamente 1 hora e 30 minutos, destinados à construção de brinquedos pelas crianças, perfazendo um total de 6 horas de filmagem. Os dados foram analisados microgeneticamente (GÓES, 2000) e episódios com falas e expressões gestuais foram selecionados e descritos em turnos (SMOLKA, 1991), a fim de caracterizar o processo criativo.

Ao fim das construções criativas, foi elaborado um CD-ROM com as imagens das criações infantis e sua devida caracterização (nome do inventor, data da invenção, materiais necessários a sua consecução e modo de confecção), com o intuito de veiculação dos pressupostos erguidos pela realização do trabalho.

\section{Resultados e Análise}

\section{$\underline{O}$ processo criativo}

Episódio 1

Uma das crianças (criança 1) solicitou miçangas e, com elas nas mãos, indagou:

1. Criança 1: O quê que eu faço aqui?

2. Pesquisadora: Tem várias miçangas, dá pra fazer um colar.

3. Criança 1: Eu faço pra vender.

4. Pesquisadora: Não acredito, nossa! Você faz junto com a sua mãe ou sozinha?

5. Criança 1: Eu faço sozinha.

Ao ouvir a conversa, a criança 2 perguntou:

6. Criança 2: O quê?

7. Criança 1: Eu faço pra vender miçanguinha. Quem quiser comprar!

\section{Episódio 2}

As crianças 3, 4, 5 e 6 partiram para a caixa de sucatas, e com a ideia de construir móveis para a casa da Barbie, começaram a pensar o que poderiam fazer.

As crianças 4 e 5 decidiram fazer uma cama para a casa da Barbie, já a criança 3, optou pela geladeira e a criança 6 fez um armário. No manuseio com os materiais, a pesquisadora foi auxiliando-as na confecção do que se propunham a fazer, mas as ideias das crianças iam surgindo no decorrer do processo. A criança 3, ao visualizar a criança 4 enchendo um balão, falou:

1. Criança 3: Ah! Fazer um balãozinho bem pequenininho. Faz o travesseiro!

2. Pesquisadora: Olha, o balãozinho dá pra fazer o travesseiro!

A criança 4 acatou então a ideia da criança 3 e fez o que ela tinha dito, acrescentando ao suposto travesseiro, cola colorida para enfeite e fixação na cama.

3. Criança 3: Não disse Profe, que dá!

4. Pesquisadora: Essa ideia de fazer o balão de travesseiro foi muito legal. 
Quando o tempo das crianças no espaço estava se esgotando e todos já estavam ajudando a arrumar os materiais utilizados, a criança 3 perguntou à criança 6 :

5. Criança 3: O que tu fez pra Barbie?

6. Criança 6: Um armário.

7. Criança 3: A gente fez geladeira, cama, piscina, tudo.

8. Criança 3: Ó Profe, sabe o que é que tu faz pra tirar foto?

9. Pesquisadora: $O$ quê?

10. Criança 3: Tu bota tudo assim junto, parecendo uma casinha.

\section{Episódio 3}

A criança 7 remexeu várias vezes na caixa de reciclados e sucata disponíveis para elaboração de brinquedos, procurando novos materiais que pudesse testar possibilidades para uma possível criação.

1. Pesquisadora: $O$ que você vai construir?

2. Criança 7: Não sei. Não sei ainda.

\footnotetext{
Episódio 4

1. Criança 8: Onde tá o balão?

2. Pesquisadora: O Balão? Tá aqui ó! O que você quer fazer? Vem fazer comigo!

E juntas, a pesquisadora e a criança 8 , foram enchendo os balões com painço. Tiveram a ideia de colocar na boca do balão um canudo para melhorar a entrada de painço. Depois, a pesquisadora sugeriu que colocassem outro balão do outro lado.

3. Pesquisadora: $O$ que isso parece?

A criança começou a sacudir o que tinham feito.

4. Pesquisadora: - Agora parece um chocalho.

E a criança foi em frente à câmera e disse:

5. Criança 8: - Olha o meu! (E começou a dançar e a movimentar sua criação, que produzia um som para sua dança). Depois veio pedir ajuda: - Eu quero encher esse balão com isso (painço). É que meu amigo quer brincar.
}

\section{Episódio 5}

A criança 9 perguntou, com um pedaço de papelão na mão:

1. Criança 9: Podes tentar fazer uma faca, aquela faca de cortar?

2. Pesquisadora: Acho que eu consigo fazer, ou então, sabe o que dá pra gente fazer?

3. Criança 9: Ãh?! É que eu to fazendo o kit com eles.

4. Pesquisadora: - Tá, então vamos fazer o seguinte, lá em cima (da mesa) tem canetinha, dá pra gente desenhar e depois cortar, o que tu achas?

5. Criança 9: - Boa ideia. (Acatando a ideia, a criança desenhou a faca, que queria fazer com o papel, e cortou o papel no formato desejado)

Zanella, Balbinot e Pereira (2000, p. 543) evidenciam que "a obra da criação apoia-se sempre sobre formas existentes e em necessidades que são historicamente produzidas", bem como salientam que o primeiro passo do processo de imaginação criadora é a percepção de si como sujeito e a percepção daquilo que o circunda, a partir do processo de apropriação das significações. Isso significa que o sujeito que cria não retira suas ideias do nada, mas da realidade 
e das suas experiências que são re-elaboradas. No episódio 1, a criança 1 retira sua ideia de fazer um colar com miçangas, das experiências que já teve em realizar sozinha essa atividade anteriormente, bem como a criança 9 do episódio 5 idealiza em um pedaço de papelão um objeto da realidade: a faca.

Para Vigotsky (1998, p. 38 apud COSTA, 2004, p. 44), no processo criativo, "não há invenções individuais no sentido restrito da palavra, em todos há sempre uma colaboração anônima”. Claro que o autor não somente se referia à intervenção direta do outro durante o processo criativo, mas a intervenção de todos os conceitos e significações culturais apropriados e re-significados pelo autor em sua criação. Sendo que a obra criada como arte, mesmo parecendo produto de um indivíduo isolado, expressa elementos sociais que incorporam os aspectos mais íntimos do criador. No episódio 1, a proposta da pesquisadora fez suscitar, na criança 1, sua lembrança de que sabia e já tinha feito colares, além disso, suscitou a intenção de venda da criança ao produzi-los.

Vigotsky (1998 apud COSTA, 2004) aponta que a inadapatação, como fonte de necessidades, desejos e sonhos, é base de toda ação criadora. A criança 1 deseja, ao produzir seu colar de miçangas, poder vendê-lo (Turno 7). Esse desejo não deixa de estar ligado ao processo capitalista de compra e venda que engendra a sociedade ocidental, na demonstração de que a obra criadora é produto de sua época e de seu ambiente (COSTA, 2004), refletindo nela a totalidade das relações sociais em que foi concebida.

Vigotsky (2003) assume a posição de que o processo criativo parte de uma experiência real, transforma-a e materializa-a, e essa obra criativa pode ser novamente alvo de outras transformações, como num ciclo que só se fecha quando o processo assume uma forma material. Nesse sentido, "a atividade criadora, além de resultar na materialidade da obra, reverte-se na constituição do sujeito que a construiu” (ZANELLA, BALBINOT e PEREIRA, 2000, p. 543). No caso do episódio 1, a atividade criadora resulta em um colar e também em uma vendedora de colar.

Apresentando-se como um ciclo que parte da realidade e volta para ela, o processo criativo condiciona-se pela imaginação e pela curiosidade. Conforme Zanella, Balbinot e Pereira (2000), a imaginação permite ao homem re-elaborar e re-significar a realidade pela combinação inusitada de seus elementos, o que possibilita visualizar o diverso e o diferente naquilo que é conhecido. Já a curiosidade, segundo Ferreira (1999) diz respeito: 
1) à qualidade ou caráter daquele ou daquilo que é curioso;

2) ao desejo de ver, saber, informar-se, desvendar, alcançar etc.;

3) ao interesse;

4) ao desejo de aprender, conhecer, investigar determinados assuntos;

5) ao desejo irreprimível de conhecer os segredos, os negócios alheios; bisbilhotice, indiscrição;

6) a informação que revela algo desconhecido e interessante. Essa denominação remete à dimensão do prazer, do desejo e do interesse, perdida, na maioria das vezes, no processo de escolarização. Uma dimensão que precisa ser resgatada, como mostra Bustos (1982), já que supõe o re-direcionamento do olhar sobre a criança e sobre a postura de todos que se envolvem no processo de relacionamento com o outro, principalmente aqueles que estão envolvidos com a escola e o processo de ensino-aprendizagem. Cabe ao psicólogo, com esse novo olhar, resgatar, nesse contexto, essa tão desprezada e importantíssima dimensão humana, a curiosidade.

A curiosidade pode se constituir como uma das possíveis características de uma atitude criativa. Entendendo que, no processo criativo, é impossível separar o intelectual e o emocional, abre-se uma possibilidade de resgate da dimensão do prazer na escola através do incentivo e do trabalho com a atividade criadora, que possibilitará a manifestação da curiosidade.

No episódio 5, com a criança 9, seu desejo eminente no momento seria a elaboração de uma faca de brinquedo com o papel que tinha em mãos, e sua vontade de saber como realizar esse intento a levou a perguntar ao outro se poderia fazer a faca para ela. A criança 9 ficou surpresa com a sugestão da pesquisadora de que ela própria poderia fazer o brinquedo tomando certo caminho em sua produção. Dessa forma, a criança 9 ocupou o lugar de autor da obra e elaborou, com satisfação, o que pretendia de antemão, apreendendo como realizar o processo.

A consideração da dimensão do desejo do outro lhe dá o direito de ser considerada como ser de direitos, como ser pensante e capaz de realizar e apreender atividades cotidianas, bem como lhe dá o status de sujeito que interfere e é modificado pela realidade que o cerca. Assim, considerando o aspecto criativo infantil, considera-se também sua atualidade vivencial, ou seja, deixa-se de considerar a criança como um vir-a-ser e passa-se a encará-la como sujeito produtor e produto da história.

No momento da elaboração criativa, considerando a criança em sua atualidade vivencial, ocorre, conforme Vigotsky (2001 apud Costa, 2004), uma emoção dialética de complexa luta interna que se concluiria na catarse, quando, numa obra de criação, a percepção de todos os seus 
elementos é retirada do automatismo e tornada consciente e perceptível pela materialização das ideias. Isso pode ser exemplificado pelo momento de elaboração da criança 7 (Episódio 3), que se concluiria pela materialização de um brinquedo ideal.

A elaboração criativa proporciona trocas afetivas e uma convivência alegre e descontraída, que permite às crianças, ao trabalharem suas fantasias, estabelecerem vínculos com o meio-ambiente no qual estão inseridas e conseguirem ingressar e participar da vida cultural, viabilizando a emergência do sujeito social (RIGHETTI, 1998), como demonstram as crianças do episódio 2, que decidem elaborar um brinquedo (a Barbie) referente a uma animação veiculada por sua cultura. Nesse processo, a criatividade se coloca a serviço da realização imaginária do desejo de elaborar móveis para a casa da Barbie, que se expressa pela representação em atos simbólicos constituídos pela materialização do desejo no objeto, nesse caso, a cama, a geladeira, o armário e a piscina.

Quanto ao produto criativo, o episódio (4) leva a reflexão de que, conforme Costa (2004), trata-se de um objeto concreto singular, que é socialmente significado por um sujeito que o admira. Nesse sentido, só se manifesta pela relação que o sujeito estabelece com ele e com o contexto, no caso, a criança 8 investe significado ao que elaborou no momento em que dança em frente à câmera chacoalhando sua criação. A criança relaciona-se com o produto de sua ação e com o contexto no qual ele estava inserido, deslocando-se de uma realidade familiarizada para uma realidade que lhe permitia ser capaz de sentir e refletir, atribuindo à criação a função e o significado de ser um chocalho.

Diante dessas considerações, Vigotsky (2001 apud COSTA, 2004) afirma que a criação infantil tem um valor pedagógico incomum em termos educativos, uma vez que, através dela, a criança não somente domina o sistema das suas vivências, mas supera-os. Há que se primar, nesse processo, pela liberdade de criação, pelo reconhecimento da originalidade da criação infantil e a renúncia à equiparação ao adulto, pelo entendimento de que criar também se constitui como necessidade da criança e pela aceitação de que a criança possui possibilidades criadoras e não somente se revela nela um futuro criador. 


\section{Mediação e Zona de Desenvolvimento Proximal}

\section{Episódio 6}

1. Pesquisadora: - Ah!!! Eu ia fazer um cofre! Alguém quer fazer um cofre?

2. Criança 10: - Eu quero fazer um cofre.

3. Pesquisadora: - Vamos fazer um cofre? Então vamos.

Ao tentar iniciar a colagem, falou:

4. Criança 10: - A gente começa assim oh!

Mas, não conseguindo efetuar seu intento, logo exclamou, entregando a lata e o pacote com cola à pesquisadora:

5. Criança 10: - Ai! Bota tu!

6. Pesquisadora: - Vamos juntas então?

A pesquisadora propôs que colassem juntas, mas logo a criança 11 já pegou a lata na mão e sozinha fixou o papel com cola ao redor.

Esse elemento foi sendo confeccionado com, cada vez menos, a interferência da pesquisadora. Ao final da criação, a criança 11 já havia acrescentado ao cofre detalhes artísticos com cola colorida. $\mathrm{O}$ cofre foi concluído.

É fácil perceber a manifestação do elemento da brincadeira nas crianças, que, para Vigotsky (1981, apud RAMALHO, 2000) é o que cria a zona de desenvolvimento proximal, ampliando as capacidades e possibilidades infantis. Brincar, como qualquer relação humana, é um processo mediado. Nesse processo, a imaginação permite à criança desvincular-se das situações concretas e construir novas relações sobre elas. Essa construção de correlações de imagens permite que surjam novas imagens e a atitude criativa vai acontecendo à medida que essas correlações sejam manifestadas no mundo real.

Conforme Vigotsky (1991 apud RAMALHO, 2000), o incentivo adulto à criação infantil explicita aquilo que permeia toda relação do homem com o mundo: a mediação. A mediação de instrumentos e signos se caracteriza pela intervenção de um elemento intermediário na relação entre homem e ambiente, assim, toda relação humana não é direta, mas mediada. O indivíduo se desenvolve dentro de um grupo cultural que lhe possibilita formas de perceber e organizar o real, formas estas que se constituem como instrumentos psicológicos que farão a mediação entre o sujeito e o mundo. Através das interações com os outros indivíduos e com o ambiente cultural é que ocorre o desenvolvimento psicológico do sujeito. Pela mediação, constitui-se o que Vigotsky (1991 apud RAMALHO, 2000) denominou de zona de desenvolvimento proximal, que se refere ao que a criança consegue fazer hoje com auxílio de outra pessoa e amanhã conseguirá realizar sozinha. 
Uma das possibilidades de mediação do outro no processo de incentivo à criação está na busca de alternativas de soluções de problemas, bem como no processo de individualização do sujeito, que dá-se a partir das relações sociais (COSTA, 2004). Assim, o desenvolvimento humano é visto como cultural, e o sujeito, como em construção e permanente movimento, em que as relações sociais estão na gênese de todas as funções individuais.

Outra possível estratégia de mediação, nesse processo de incentivo à criação, é o favorecimento ao desenvolvimento da autonomia da criança. Isso pode ser exemplificado no episódio 6 pela postura da pesquisadora (estagiária de Psicologia), ao não assumir a ação para si diante do pedido da criança que não consegue realizar sozinha o que pretende e propor que ambas façam juntas o que é pretendido (turno 6). Trabalha-se nesse sentido, no intuito de criar a zona de desenvolvimento proximal para que a criança que é auxiliada hoje a fazer alguma coisa consiga realizá-la sozinha amanhã, como foi evidenciado na criança 10.

\section{$\underline{\text { Desenvolvimento da psique humana }}$}

\section{Episódio 7}

A criança 11, depois de algum tempo mexendo nos materiais reciclados, colocou em frente ao rosto um pedaço quadrado de EVA, e permaneceu mais ou menos uns cinco minutos como ele no rosto. Depois, fez um recorte para dois olhos e para a boca e, colocando a folha de EVA recortada no chão, pintou com guache e cola colorida o que denominou de máscara.

Um dos arcabouços teóricos de Vigotsky (2003) sobre o desenvolvimento da psique humana está na ênfase às ações como motor do desenvolvimento, entendendo que a atividade humana apresenta três aspectos fundamentais, conforme Zanella (2004): ser orientada por um objetivo; ser mediada; e produzir algo cultural, físico e/ou simbólico, e que consiste na objetivação do ser humano. Nesse sentido, a criança 11 agiu, ao produzir sua máscara, objetivando as ideias que teve nos instantes em que punha o EVA em frente ao rosto. A criança 11, com o objetivo de construir algo com o material, manipulou-o, idealizou-o e colocou seu projeto em prática, dando novas formas ao material, atingindo o objetivo de elaborar um brinquedo.

O que mostra a criança 11, nesse processo, é uma apropriação da atividade em si que, conforme Zanella (2004), se refere à utilização adequada dos mediadores da ação (instrumentos 
e/ou signos) como uma condição para a emergência do novo, em que o sujeito, com postura de autor, parte de uma realidade conhecida e dialoga com ela; transformando-a e a si mesmo, nesse processo, objetiva sua subjetividade e torna-se autor das próprias ideias.

$\underline{\text { As possibilidades do manuseio com sucata e material reciclável }}$

\section{Episódio 8}

1. Criança 12: - Eu não me canso de fazer brinquedo não.

2. Pesquisadora: - Ah! Não?

3. Criança 12: - Não.

4. Pesquisadora: - Tu gosta de fazer brinquedo?

5. Criança 12: - Adoro até.

6. Pesquisadora: - Que bom! Por que tu gosta de fazer brinquedo?

7. Criança 12: - Não sei, eu gosto de fazer coisas novas. Eu não fico só com os brinquedos que tenho, eu invento coisas novas.

8. Pesquisadora: - Que coisa boa! E isso te faz bem?

9. Criança 12: - Me faz.

10. Pesquisadora: - Nem sempre os brinquedos que tu tens é o que tu quer, né?

11. Criança 12: - É, da.

Considerando as ideias de Vigotsky (2003) de que, quanto mais rica a experiência mais abundante deverá ser a fantasia, torna-se bastante importante o incentivo a experiências como o manuseio com diversos materiais e a possibilidade de re-criação e re-significação sobre eles, pois, além de ampliar as possibilidades de se dar sentido à vida de um modo geral, gera possibilidades de identificação do sujeito com o mundo em que se insere.

Nesse sentido, Machado (1995) entende que a sucata, os restos, os refugos, são elementos ricos para brincar de maneira espontânea e criativa. Tais elementos, em princípio, trazem consigo o elemento da transformação, pois, não sendo estruturados, instigam a ação da própria criança para que a brincadeira aconteça; vêm também como promotores de um novo olhar acerca da realidade (turno 5), trazendo consigo a possibilidade de enriquecê-la (turno 7). No episódio 8, a criança 12 incorpora toda essa concepção de Machado (1995) ao manifestar o quanto gosta de poder transformar a realidade de acordo com aquilo que pretende. A criança encontra, na possibilidade de manipular materiais para construir o brinquedo que quiser, a sua capacidade de mudar a realidade, de transformá-la; também encontra uma possibilidade de ser ouvida e de fazer valer os seus desejos. Nesse sentido, a criança 12 passa a se interessar por essa nova forma da animação cultural que tem possibilidade de entrar em contato: a elaboração de brinquedos com sucata e material reciclável. 


\section{Considerações finais}

A criatividade, como uma manifestação de experiência pessoal, constitui-se pelo processo de objetivação, em que o implícito do ser humano se materializa pela transformação do real e do sujeito que o concebe. Assim, a obra criativa leva a supor a dimensão subjetiva daquele que a elaborou e, com isso, sua dimensão do prazer. O prazer, o desejo, a vontade, a crença, são aspectos fundamentais a serem considerados em qualquer relacionamento humano. Toda relação humana, sendo mediada, implica dimensões sociais e individuais do homem, bem como implicam suas dimensões intelectuais e emocionais que formam uma unidade e fazem parte do conjunto maior que é a identidade do sujeito.

Nesse estudo do complexo processo criativo, algumas considerações podem ser levantadas, talvez, no intuito de quebrar paradigmas ou de fazer supor que a ação humana criativa possa ser incentivada. A primeira consideração se refere à ilusão clássica de que criar é tirar algo do meio do nada e impactar a realidade com isso. No entanto, o processo criativo, como uma atividade humana, não se desvincula da realidade, pelo contrário, o reconhecimento da realidade e a experiência com ela reforçam e ampliam ainda mais as possibilidades de criar. Por alguma necessidade daquele que cria, ele associa e dissocia aspectos vividos que anteriormente não tinham relação e, diante de uma realidade, transforma-a e transforma a si mesmo nesse processo: um ser humano completo que dirige suas ações com o objetivo de materializar sua interioridade. Assim, o processo de criar é cotidiano, bem como individual e social ao mesmo tempo, uma vez que toda a ação de um sujeito, que se constitui sócio-historicamente, traz consigo as ações de todos aqueles que fazem e fizeram parte de sua história. Nesse sentido, a obra criativa expressa todo contexto que o sujeito criador está inserido.

Na consideração de que, no processo de escolarização ocidental, a dimensão da vontade e do prazer está sendo substituída pelo pragmatismo, pela intolerância e pelo funcionalismo exacerbado, há a necessidade do desenvolvimento de atividades que funcionem como propulsoras de reflexões em torno dessa realidade e em torno de busca de alternativas para que qualquer um seja criança, adulto, pai, professor, técnico, administrador na escola - possa externar seus sentimentos, suas vontades, suas ideias, a fim de que o complexo grupo se (re)conheça melhor, respeite um ou outro e considere que o grupo como um todo seja o responsável pelo sucesso no alcance de um dos objetivos maiores da escola: a socialização da criança. 
Assim, considera-se a promoção da transformação dessa realidade, através da atividade criativa das crianças, uma proposta de incentivo ao protagonismo infantil no contexto escolar. Nesse contexto, seria interessante ouvi-las, cada vez mais, em seu desenvolvimento, no cotidiano de suas grandes manifestações através do brincar. A elaboração de perspectivas levando em conta essa possibilidade é um esforço que o profissional dentro da escola pode realizar para que os desejos e a voz da infância sejam ouvidos e considerados nesse contexto. Nesse sentido, de um contexto escolar feito para a criança passa-se a um lugar feito pelas crianças.

As discussões que a observação sistemática das atividades criadas (brincadeiras), desenvolvidas pelas crianças, levam a questionamentos das estruturas sociais existentes. A proposta de reorganização legal do acesso ao Ensino Fundamental exige que se observe com mais atenção o processo de construção do pensamento pelas crianças. Assim como neste estudo, oriundo de um projeto piloto, elementos são destacados para a análise e enriquecem diretamente o conhecimento dos envolvidos, conhecimento este que pode ser potencializado na formação inicial e continuada dos professores, psicólogos e outros profissionais, através de seminários, cursos, publicações e outras formas de exposição dos resultados atingidos.

Desta forma, configura-se essencial a função de um Laboratório no interior de uma instituição educacional universitária, articulando-se o ensino, na formação básica e universitária de pesquisa e de extensão, via a publicação e apresentação dos resultados em eventos acadêmicos.

\section{Referências}

BUSTOS, Elena Noseda et al. Psicodrama pedagógico. In: BUSTOS, Dalmiro M. e colab. O psicodrama. Aplicações da técnica psicodramática. São Paulo: Summus, 1982.

COSTA, Fabíola Cirimbelli B. O olho que se faz olhar: os sentidos do Espaço Estético do CA/UFSC para alunos da Educação Física. Florianópolis: UFSC, 2004. (Dissertação de Mestrado).

FERREIRA, Aurélio B. de H. Novo Dicionário Aurélio - Século XXI (Versão Eletrônica 3.0). Editora Nova Fronteira e Lexikon Informática, 1999. 
GÓES, Maria Cecília R. A abordagem microgenética na matriz histórico-cultural: uma perspectiva para o estudo da constituição da subjetividade. Cadernos Cedes, n. 50. Campinas: Papirus, 2000.

MACHADO, Marina M. O brinquedo-sucata e a criança: a importância do brincar, atividades e materiais. 2. ed. São Paulo: Loyola, 1995.

MEIRA, Luciano. Análise microgenética e videografia: ferramentas de pesquisa em psicologia cognitiva. In: Temas em Psicologia - SBP. Ribeirão Preto - SP: FCA, 1994. n. 03. p. 59-71.

PETERS, Leila Lira (Org.). Relatório parcial 2004. Florianópolis, Colégio de Aplicação, Centro de Ciências da Educação: UFSC, 2004.

PINTO, Manuel; SARMENTO, Manuel Jacinto. As crianças e a infância: definindo conceitos, delimitando o campo. In: PINTO, Manuel; SARMENTO, Manuel Jacinto. As crianças: contextos e identidades. Portugal: Ed. Universidade do Minho, 1997.

RAMALHO, Márcia T. de B. A brinquedoteca e o desenvolvimento infantil. Florianópolis: UFSC, 2000. (Dissertação de Mestrado).

RIGHETTI, Amélia Maria L. A atividade criativa como introdutora da criança na experiência cultural, Rio de janeiro: UFRJ, 1996. (Dissertação de Mestrado).

SMOLKA, Ana Luísa. A prática discursiva na sala de aula: uma perspectiva teórica e um esboço de análise. In: Cadernos Cedes, Campinas-SP: Papirus, n. 24. p. 51-65, 1991.

SOLÉ, Maria de B. O jogo infantil: organização das ludotecas. Lisboa: Instituto de Apoio à Criança, 1992.

VYGOTSKY, Lev S. La imaginación y el arte en la infancia: ensayo psicológico. 6. ed. Madri, Espanha: Ediciones Akal, 2003.

ZANELLA, Andréa Vieira. Atividade, significação e constituição do sujeito: considerações à luz da psicologia histórico-cultural. In: Psicologia em Estudo, 2004, v. 09. n. 01. p. 127-135. 
ZANELLA, Andréa Vieira; BALBINOT, Gabriela; PEREIRA, Renata Susan. Re-criar a (na) renda de bilro: analisando a nova trama tecida. In: Psicologia: Reflexão e Crítica, 2000, v. 13. n. 03. p. 539-547. 